\title{
Spanenglish phoenix: Utilização de projeto educacional de língua estrangeira como estratégia motivacional para o aprendizado
}

\author{
Spanenglish Phoenix: Use of a foreign language educational project as a \\ motivational strategy for the learning
}

\begin{abstract}
Weber Pires
Mestrando em Ciências da Educação pela The Grendal College and University, Docente de Língua Inglesa e Espanhola da Escola Estadual de Educação Profissional Rita Aguiar Barbosa, Itapipoca, Ceará, Brasil. E-mail: weber_pires@ hotmail.com Roberta Ramos Frota Bezerra

Mestre em Logística e Pesquisa Operacional pela Universidade Federal do Ceará, Docente do Instituto Vale do Acaraú, Docente da Escola Estadual Profissional Rita Aguiar Barbosa, Itapipoca, Ceará, Brasil. E-mail: robertafbezerra.adm@gmail.com Felipe Julio Leite Farias

Pós Graduado em Fisiologia do Exercício pela Faculdade Montenegro. Docente de Educação Física da Escola Estadual de Educação Profissional Rita Aguiar Barbosa, Itapipoca, Ceará, Brasil. E-mail: felipej16@gmail.com Ana Maria Sousa Farias

Pós Graduada em Gestão Escolar pelo CAED. Diretora da Escola Estadual de Educação Profissional Rita Aguiar Barbosa, Itapipoca, Ceará, Brasil. Email: amsf2005@hotmail.com

Resumo: Objetivou-se relatar a experiência acerca da implementação de um projeto educacional voltado a motivação para o aprendizado em língua estrangeira desenvolvido com adolescentes na faixa etária entre 14 e 17 anos matriculados no ensino médio integrado de uma Escola Estadual do estado do Ceará. Foi fundamentado com base na pedagogia de projetos e possibilitou reafirmar que o desenvolvimento cognitivo do aluno se dá por meio da interação social, ou seja, de sua interação com outros indivíduos e com o meio onde ele está inserido, bem como a importância da motivação nesse processo. Assim, possibilitou refletir acerca das potencialidades e possíveis mudanças para o enfrentamento dos desafios no ensino de línguas estrangeiras e que a partir da sócio-interação constatou-se o avanço dos educandos abrindo um contraponto da dinâmica dos trabalhos individuais para seguirem de encontro ao trabalho em conjunto corroborando para a mudança de olhar no que se refere ao aprendizado das línguas estrangeiras.
\end{abstract}

Palavras-chave: Aprendizagem; Ensino de Língua estrangeira; Pedagogia de Projetos.

\begin{abstract}
The objective was to report the experience about the implementation of an educational project focused on the motivation to learn in a foreign language developed with adolescents between the ages of 14 and 17 enrolled in the integrated high school in a public school in the state of Ceará. It was based on the pedagogy of projects and made it possible to reaffirm that the student's cognitive development occurs through social interaction, that is, his interaction with other individuals and the environment where he is inserted, as well as the importance of motivation in this process. Thus, it was possible to reflect on the potentialities and possible changes to face the challenges in the teaching of foreign languages and that from the socio-interaction it was verified the progress of the students, opening a counterpoint of the dynamics of the individual works to follow the work in corroborating to the change of look regarding the learning of foreign languages.
\end{abstract}

Keywords: Learning; Foreign language teaching; Project Pedagogy 


\section{INTRODUÇÃO}

Educar é um processo que ocorre por meio das próprias relações que desenvolvemos, seja um ato intencional ou não. Esse processo abrange diferentes tipos de formação e ambientes. Em vista desse aspecto, um debate acerca da importância do trabalho pedagógico em sala de aula vai muito além dos muros da escola. Com isso, o conhecimento de uma língua estrangeira (LE) vem sendo amplamente difundido e exigido nos diversos contextos da contemporaneidade sendo o espaço de aprendizagem um ambiente que necessita de uma nova significação no ensino de LE já que sua função está além dos propósitos utilitários da língua (TEIXEIRA; RIBEIRO, 2012).

Mesmo conceituando educação dentro de um processo informativo é preciso compreender que educar é uma combinação de valores morais, atitudes, emoções e motivações inerentes ao ser humano e que estão também influenciando nesta pratica, entre o ensinar e o aprender. Dessa forma, quando se fala em educar, estamos nos referindo, também, a influencia dos aspectos econômicos sociais e políticos (DELORS, 2001).

Se em um determinado ambiente não houver instrumentos e métodos que possibilitem o ensino, esse aluno poderá estar fadado ao insucesso, e consequentemente terá problemas para concluir esse aprendizado já que não terá o suporte adequado para esse fim. O ser humano é capaz de aprender outro idioma, assim como ele aprende a sua língua materna. Estudos recentes na área têm mostrado que o que falta hoje na sala de aula, é a satisfação do profissional bem como, formação continuada, a falta de políticas públicas, condições de trabalho e o interesse do aluno (ROCHA, 2008).

Em grande parte das escolas particulares de ensino fundamental e médio, o ensino de LE tem ficado restrito à explicação de regras gramaticais, a exploração de textos curtos não complexos e ao treinamento intensivo para resolução de questões de múltipla escolha, que no máximo, permitem resultados medianos nos processos seletivos de acesso ao ensino superior. A proposta nas escolas públicas parece ser a mesma, mas na prática, os resultados são ainda mais modestos. Pesquisas revelam que o ensino da língua inglesa na maioria das escolas públicas está limitado à apresentação das regras gramaticais mais básicas, exemplificadas com frases curtas e descontextualizadas, treinadas em exercícios escritos de repetição e de substituição típicos do audioligualismo (SANTOS, 2011).

O ensino de idiomas é de suma relevância para quem deseja se qualificar como cidadão do mundo, ele faz com que as pessoas ultrapassem fronteiras e consequentemente faz parte de um futuro onde todos se comunicam, com mais eficácia e rapidez. É importante que o aluno esteja inserido em um ambiente que proporcione um aprendizado focado no aspecto cognitivo psicológico e afetivo dele. È notório de que quanto mais cedo à criança começar a aprendizagem de línguas mais facilmente ela irá aprender. Porém não é somente a idade que interfere no ensino, há também outros fatores biológicos e contextuais para que ela aconteça.
Assim a pedagogia de projetos em língua estrangeira tornou-se uma estratégia de ensino e um aliado no processo de aprendizagem. Trata-se de projetos escolares que são trabalhos formais e científicos, porque seguem as normas e os procedimentos da metodologia científica, visando alcançar certo resultado pela realização de um estudo e de uma busca de informações (SILVA, 2011).

Sendo assim, este estudo tem o objetivo de apresentar o relato de experiência de um projeto educacional de língua estrangeira com a finalidade de despertar o interesse dos educandos do ensino médio acerca do aprendizado das línguas inglesa e espanhola. Foi fundamentado com base na pedagogia de projetos e possibilitou a reflexão acerca das possibilidades e possíveis mudanças para o enfrentamento dos desafios no ensino de línguas estrangeiras.

\section{METODOLOGIA}

Trata-se de um estudo descritivo do tipo relato de experiência desenvolvido numa escola estadual no estado do Ceará. A Escola possui quatorze salas de aula, uma biblioteca, uma sala de multimídias, um laboratório de enfermagem, um Laboratório de Hardware, um laboratório de informática, um laboratório de ciências, um laboratório de física, diretoria, secretaria, sala da coordenação, sala de professores, sala de Diretor de Turma, sala de Turismo, sala do Grêmio Estudantil, almoxarifado, depósito para material de limpeza, banheiros masculinos e femininos, cantina, cozinha, praça de alimentação, quadra poliesportiva e jardins, totalizando $4.945,93 \mathrm{~m}^{2}$ de área construída. O quadro de profissionais é composto por quinze funcionários, trinta e dois professores pós-graduados atuando em áreas específicas e pelo Núcleo Gestor constituídas pela Diretora, um coordenador da área profissional, um coordenador da área pedagógica e um para assuntos acadêmicos, o secretário escolar e um técnico financeiro.

Tem como premissas o protagonismo juvenil onde o jovem é visto como centro do processo de aprendizagem e capaz de realizar ações com autonomia, compromisso, prontos para atenderem às exigências sociais e profissionais; formação continuada onde os educadores passam por um processo de qualificação contínua e são preparados para a implementação de práticas educativas eficazes; Atitude Empresarial Sócio Educacional buscando resultados concretos, satisfazendo a comunidade e investidores além de priorizar a adoção de uma postura empreendedora articulando recursos humanos e materiais; por fim, a corresponsabilidade pela educação onde clientes e investidores são comprometidos com o desenvolvimento da proposta educativa da escola.

A pedagogia de projetos infere que a aprendizagem baseada em projetos enquanto método de pesquisa estimula os alunos a adquirir conhecimentos e habilidades, o que possibilita a interdisciplinaridade. Além de aprender os alunos têm a oportunidade de trabalhar em equipe e desenvolver valores (FERNANDEZ, 2012).

O projeto foi intitulado SpanEnglish Phoenix, e para sua operacionalização a turma do terceiro ano de redes ficou responsável pela organização, eles sortearam para cada turma da escola uma serie americana onde deveriam representar na forma de musical suas apresentações com o 
uso do idioma inglês e espanhol. A motivação para a escolha das series se deu devido a popularidade desses seriados no contexto da faixa etária da adolescência.

Foram organizados treze monitores que ficaram responsáveis para orientar as turmas individualmente, com a finalidade de tirar dúvidas, fazer sugestões e monitorar e auxiliar nas pronúncias da língua inglesa. Com isso, foi observada a importância das tecnologias digitais para aperfeiçoar suas pronúncias e também expandir o conhecimento cultural dos idiomas em questão. Os alunos usaram as horas de intervalo entre os turnos já que a escola funciona em tempo integral, além da dedicação nos finais de semana para assim realizar suas praticas orais e expressões corporais.

Para a organização do evento foi necessário levantar recursos para prover estrutura de palco, som e iluminação e para este fim os alunos conseguiram patrocinadores para a montagem de palco, iluminação e som além também de realizar o convite a professores de arte, dança e de língua inglesa e espanhola para julgar as apresentações, esse projeto foi desenvolvido no período de 45 dias corridos.

Nesse período muitos dos professores notaram a aplicação pessoal de cada aluno, pois os que não iriam se apresentar ficaram responsáveis por criar um diário de bordo, e neste deveria conter fotos e depoimentos de todos os dias de orientações, também deveria ser bilíngue. No momento da culminância do projeto estavam presentes 516 alunos e cerca de 1000 convidados.

A abertura do projeto se deu com entrada de bandeiras representando os países de língua inglesa e espanhola, com um grupo de alunos cantando musicas em inglês e em espanhol de bandas renomadas, em seguida houve a palavra da diretora da Instituição e dos professores de Inglês e espanhol envolvidos diretamente no projeto.

A apresentação das turmas no evento se deu da seguinte forma: primeiros anos conforme suas turmas: Administração, Comércio, Enfermagem e Redes de Computadores; segundos anos: Administração, Comércio, Enfermagem e Redes de Computadores; terceiros anos: Comercio, Enfermagem, Hospedagem e Redes de Computadores.

Os jurados receberam fones de ouvido, um script de cada apresentação e os quesitos para serem avaliados que foram: performances, pronúncia dos idiomas inglês e espanhol, assiduidade, permanência na escola até a ultima turma se apresentar.

\section{RESULTADOS E DISCUSSÃO}

O projeto educacional de língua estrangeira como instrumento motivacional, veio reafirmar que o desenvolvimento cognitivo do aluno se dá por meio da interação social, ou seja, de sua interação com outros indivíduos e com o meio onde ele está inserido. $\mathrm{Na}$ abordagem vygotskyana, a aprendizagem ocorrerá através da interação de um indivíduo com os outros em conjunto ou em pares, o que se constituirá como subsídio para o desenvolvimento da competência comunicativa já que nesse contexto está em constante negociação e mediação (ROZENO; SIQUEIRA, 2011).

$\mathrm{O}$ que acontece não é um resultado entre fatores inatos e adquiridos e sim uma interação dialética que se dá, desde o nascimento, entre o homem e o meio social e cultural em que está inserido. Sendo assim, constata-se que o desenvolvimento do ser humano é compreendido não em decorrência de fatores isolados que amadurecem, nem tampouco de fatores do meio em que está inserido e que agem sobre o organismo controlando seu comportamento, mas sim como o resultado de trocas recíprocas, que se estabelecem durante toda a vida, entre o homem e meio, cada aspecto influindo sobre o outro (LOPES et al., 2011).

Inicialmente houve certa resistência por parte de alguns educandos que estiveram relacionadas à baixa motivação e falta de confiança o que para Krashen (1985) indica que estes quando tensos, ansiosos e com baixa estima, são propensos a elevar o nível de seu filtro afetivo e na maioria das vezes formam um tipo de bloqueio mental, reduzindo, assim, sua capacidade de absorção de conhecimento. Aqueles que possuem atitudes que não são ideais com relação à aquisição de uma segunda língua, não apenas tenderão a procurar menos conhecimento como terão um alto filtro afetivo, e "mesmo que a mensagem seja entendida, impedirá que o conhecimento alcance a parte do cérebro responsável pela aquisição de língua, ou o LAD (Dispositivo de Aquisição de Língua)”.

A partir do andamento do projeto e a sociointeração dos alunos foi possível constatar que aptidões afetivas foram progressivamente desenvolvidas como motivação, autoconfiança e redução da ansiedade. Alunos motivados, confiantes e com baixa ansiedade estão propensos a serem bem sucedidos no processo de aquisição de uma segunda língua.

A motivação do aluno é como uma mola propulsora do engajamento e esforço dele no processo. Mediante isso, alguns expertises da área de ensino e aprendizagem de línguas desenvolveram estudos com o intuito de fornecer subsídios aos docentes que sejam como uma ponte para uma melhor compreensão do fenômeno. Também afirmam que a motivação atua como o motor inicial para gerar aprendizagem, como uma ferramenta que ajuda a sustentar a difícil jornada de se aprender uma língua estrangeira. Ressaltam ainda que a motivação é um aspecto de extrema relevância no aprendizado de uma língua, sendo assim, sem ela, mesmo com currículos apropriados ou com habilidades notáveis não são suficientes para garantir a aprendizagem do estudante. (CANATO; ROZENFELD, 2017).

O projeto SpanEnglish Phoenix voltado para motivar o ensino dos idiomas inglês e espanhol tem o objetivo de facilitar estratégias de organização entre inúmeros conteúdos ou conhecimentos escolares, interligando-os com as questões do dia a dia colocadas para os alunos, para que eles convertam tais informações em conhecimentos próprios. E isso se dá quando se trabalha direcionado com a formação de competências segundo as Diretrizes Curriculares Nacionais (MEC, 1999).

Esse projeto trouxe desafios tanto para o corpo docente quanto para o corpo discente, pois envolveu conhecimento tecnológico, dedicação, e esforço por parte de todos. Assim, seu desenvolvimento enquanto método possibilitou abordar além do aspecto pedagógico, questões sociais e de postura vindo a contribuir além das questões de natureza de ensino-aprendizagem com o contexto 
cultural onde o educando se encontra inserido (THIESEN, 2008).

Essa idéia corrobora com o que diz Pedro e Sousa (2014) onde afirmam que a pedagogia de projetos visa à promoção de um processo de ensino aprendizagem essencialmente participativo, prático e significativo já que apresenta a capacidade de articular, movimentar e acionar valores, conhecimentos e habilidades de suma importância para o sucesso de atividades necessárias no trabalho.

Dessa forma, trabalhar com projetos passa a ter grande relevância já que possibilita contemplar a integração entre teoria e pratica. Desde sua criação, por Kilpack e Dewey em 1920 nos Estados Unidos a didática do uso de projetos, tem sido revista e atualizada, além de receber outras nomenclaturas, como metodologia de projetos ou projetos de trabalho (SOUSA, 2012).

\section{CONCLUSÕES}

O desenvolvimento do projeto enquanto estratégia para motivar o aprendizado em língua inglesa e espanhola possibilitou aos educandos estabelecer no processo de ensino-aprendizagem uma interrelação a partir da esfera social, cultural e escolar alinhada com o mundo real, onde as relações entres os pares, professores e funcionários possibilitou trocas de experiências e compartilhamento de saberes.

A partir da sócio-interação foi possível perceber o avanço dos educandos sobretudo por saírem da dinâmica dos trabalhos individuais para irem de encontro ao trabalho em conjunto o que trouxe como ganho a possibilidade de modificar seus olhares no que se refere ao aprendizado das línguas estrangeiras.

$\mathrm{O}$ professor quando se compromete a realizar um trabalho como este, consegue ter uma idéia concreta de uma atividade coletiva e percebe o processo de evolução coletiva, mas vislumbra que para atingir tal resultado se faz necessário por vezes, sair da sala de aula e rever novas estratégias que contemplem a dramatização, encenação e interpretação assim como, a música e a dança.

Certamente o projeto educacional de língua estrangeira como estratégia motivacional para a aprendizagem não é a solução de todas as fragilidades, mas oportunizou a todos os envolvidos se automotivar para outras formas de approach, e avançar na quebra deste paradigma.

\section{REFERÊNCIAS}

BRASIL. Parecer 16/99 - Diretrizes Curriculares Nacionais para a Educação Profissional de Nível Técnico. Brasilia, 05/10/1999. Disponível em: <http://www.educacao.pr.gov.br/arquivos/File/pareceres/p arecer161999.pdf>. Acesso em: 08 jan 2018.

CANATO, J. B. C.; ROZENFELD, C. C. F. A motivação de alunos de alemão e prática de multiletramentos em um CEL. Pandaemonium., v. 20, n.30, p. 86-111, 2017.

DELORS, J. Educação: um tesouro a descobrir. Relatório para a UNESCO da Comissão Internacional sobre educação para o século XXI. $6^{\mathrm{a}}$ ed. São Paulo: Editora Cortez; 2001.
FERNANDES, E. David Ausubel e a aprendizagem significativa. Nova Escola, n. 248, 2011. Disponível em: <http://novaescola.org.br/formacao/david-ausubel aprendizagem-significativa-662262.shtml>. Acesso em 09 jan 2018.

KRASHEN, S. D. The Input Hypothesis: issues and implications. 4.ed. New York: Longman, 1985.

LOPES, A. F.; SANTOS, É. M. B. R.; FERREIRA, P. J. S.; BRITO, P. V. G. O desafio do uso das TIC na educação infantil. Revista Pandora Brasil., v. 1 n. 34, p. 170-184, 2011.

PEDRO, J. S.; SOUSA, D. A. Um Vínculo AfetivoCultural com a Língua Inglesa - o grande desafio. SIGNUM: Estud. Ling., Londrina., V. 1 n. 17, p. 298-321, $2014 . \quad$ Disponível em: <http://www.uel.br/revistas/uel/index.php/signum/article/ viewFile/17547/14779>. Acesso em: 08 jan 2018.

ROCHA, C. H. O ensino de línguas para crianças: refletindo sobre princípios e práticas. In: ROCHA, C.H.; BASSO, E. A. (Org.) Ensinar e aprender língua estrangeira nas diferentes idades: reflexões para professores formadores. São Carlos: Claraluz; 2008.

ROZENO, E. F.; SIQUEIRA, K. M. A teoria sóciointeracionista de Vygotsky como subsídio para a aprendizagem comunicativa da língua inglesa. Revista Eletrônica da Faculdade Sente de Setembro, v.5, n.5, 2011.

SANTOS, E. S. S. O ensino da língua inglesa no Brasil. Babel: Revista Eletrônica de Línguas e Literaturas Estrangeiras., v. 1, n.01, p. 39-46, 2011.

SILVA, W. R. Construção da Interdisciplinaridade no Espaço Complexo de Ensino e Pesquisa. Cadernos de Pesquisa., v. 41, n. 143, p.582-605, 2011.

SOUSA, L. O. A Inclusão Escolar no Contexto da Educação Infantil. Revista Aprender., v 1, n. 6, 2012..

TEIXEIRA, C. S.; RIBEIRO, M. D. A. Ensino de Língua Estrangeira: concepções de língua, cultura e identidade no contexto ensino/aprendizagem. Revista Linha d'Água, n. 25 v. 1, p. 183-201, 2012.

THIESEN, J. S. A interdisciplinaridade como um movimento articulador no processo ensino-aprendizagem. Revista Brasileira de Educação. v. 13, n. 39, p. 545-598, 2008. 